\title{
Notes on Chinese-to-English translations
}

I introduce Chinese terms through simplified Chinese characters/pinyin Romanization of Mandarin Chinese, except in some cases when I use the Chinese term or title throughout the book (e.g., Xintiandi). In cases when English translations are the same as pinyin (e.g., Shanghai), I omit pinyin.

In cases where cited authors use a system other than pinyin (e.g., WadeGiles), spellings in footnotes, quotes, and main text might differ (e.g., Mao Tse-tung versus Mao Zedong).

I write most Chinese names in pinyin following mainland Chinese conventions, with surnames before given names (e.g., Ai Weiwei). When I discuss people from outside mainland China (e.g., Hong Kong, Taiwan), I employ their own local conventions and/or the names they usually use (e.g., Wong Kar-wai, David Tang, Ang Lee).

See glossary for translations of personal names and titles. 